\title{
Some Issues with the Concept of Face: When, What, How and How Much?
}

\author{
Jim O'Driscoll \\ University of Huddersfield
}

\section{Foreword}

As this volume and numerous other works demonstrate, the concept of face has proved enormously stimulating to scholars of the interpersonal aspects of communication. Its appeal seems to lie in the possibilities it offers for examining instantiation both of the macro concept of identity and also of personal concerns such as self-esteem, self-image and reputation - things which in themselves have nothing to do with interaction - within interaction.

This paper is a wide-ranging, though patchy, discussion of the concept and our use of it. Because the concept was introduced into sociopragmatics by Goffman (1967 [1955]: 5 ), it is not possible to conduct such a discussion without quoting his original definition. Here it is:

(1) The positive social value

(2) a person effectively claims for himself

(3) by the line others assume he has taken

(4) during a particular contact

I have represented it this way so that below I can refer to its various elements as line numbers.

To start with this quote risks the inference that what follows is a kind of biblical exegesis. And indeed, so powerful and alluring is Goffman's exposition that there is a danger that discussion on this matter can be reduced to mere argumentation about 'what Goffman really meant'. This paper may appear at times to fall into this trap. But I hope it becomes clear that the reason for its exegetical tendencies are simply that Goffman's work can provide an avenue into further exploration of the concept. We scholars are, of course, unbound by any religiose affiliations and are free to suggest any modification to Goffman's concept that we deem useful (and I hope this will become clear too).

However, there are limits to what can be accomplished in just one paper. This paper begins (section 1 below) by painting a picture of what, in my view, makes face distinctly face (i.e. not just a buzzword for some other phenomenon).But it is not principally concerned with the precise nature of the concept. It only briefly engages with Arundale's 


\section{Politeness across Cultures}

(2009) objections to Goffman's concept and his alternative conceptualisation. (See section 7 below. For greater engagement, see Jakubowska, this volume.) It is chiefly concerned with the operationalisation of the concept in studies of interpersonal communication, with special reference to cross-cultural and intercultural studies.

To foreground face, and at the same time to omit the words 'politeness' and 'culture' in the title of a paper which appears in a volume entitled Politeness Across Cultures, requires some explanation. The succinct explanation is that this paper focuses on the 'across' part of this volume's title. And face, it is argued, is an ideal concept for engaging with the cross-cultural and intercultural precisely because it does not implicate specific cultures (see section 3) or construals of politeness which are inevitably culture-specific (see section 2). Having thus argued for the value of the concept of face, the remaining sections of this paper raise a series of problematical issues connected with it. These are framed as questions, to which I offer answers which are extremely sketchy but nevertheless often forthright. The main intention is to suggest an agenda for future discussion.

\section{The 'reality' of face: its reciprocality}

Imagine a podium event. It could be a paper being presented at a conference, a theatre play, a speaker at a political rally or just a teacher doing up-front chalk-and-talk in a teenage classroom. Now imagine that something very untoward happens which distracts attention from the main business, something which utterly destroys, albeit only momentarily, the credibility of the major actor. The conference presenter lets off a very loud fart, the actor forgets his/her lines in mid speech, the political speaker's false teeth come shooting out of his/her mouth or the teacher displays sudden and extreme incontinence. As a result, the victim is visibly and greatly discomfited. S/he suffers extreme embarrassment. S/he is, as the English saying goes, covered in confusion.

On the page, incidents of this kind come across as laughable. In real life they come across very differently. Typically, all those present experience the same sense of horror as the victim. They feel embarrassed for him/her. They too will be visibly discomfited. Moreover, the extent of their discomfiture, while not as great, will be in direct proportion to that of the victim. The more the latter is humiliated, with no relieving humour or subsequent new focus of attention on the horizon, the greater it will be; the more s/he is able to demonstrate poise (Goffman 1967: 8-9) - either by successfully appearing to ignore the incident entirely and just 'moving on' or by passing it off through jocularity or some other incorporation into his/her performance - the less it will be. Moreover, the other participants will eagerly cooperate in any such repair work. (If this is a joke, for instance, they will laugh loudly.)

A couple of factors could affect the precise degree of this remarkable demonstration of fellow feeling. When participants' sense of commitment to the occasion is great, we may expect the fellow-feeling to be a little greater. (In the conference scenario above, for instance, participants are there of their own willing accord, so that they assume some per- 
sonal responsibility for the proceedings.) When it is small, they may share less in the discomfiture of the main performer (as with pupils in a classroom, who are forced to be present). Similarly, interpersonal affect might play a role. Participants who personally like and identify with the victim may feel greater discomfiture than those who are in some way hostile (the pupils in the classroom, perhaps). In this latter case, they might even feel pleased at the victim's misfortune.

However, a moment's reflection allows us to realise that these factors seem to have only a minimal influence on the reactions of participants. Typically, even someone who has no commitment to the occasion and personally dislikes the victim will nevertheless be visibly discomfited. If $\mathrm{s} / \mathrm{he}$ is pleased, $\mathrm{s} / \mathrm{he}$ is secretly pleased - and for later but not for now. S/he may pass a sniggering remark to an adjacent participant, but this is not so much an attempt to further discomfit the victim as it is a response to his/her own discomfiture.

The origin of this demonstrable fellow-feeling, then, cannot be found solely in interpersonal affect or in any other particularity of the situation. It seems to be built into us as interactants. We are affectively implicated in the affective adventures of others merely by being in their presence. It is in this reciprocal nature - whereby damage to one person's face leads to the damage of everybody's face - and the repair of that face simultaneously involves the repair of all faces - that the phenomenon of face may be described as 'real'. It cannot be reduced to the outward show of inner feelings (as Brown \& Levinson's 1987 conception of 'face as wants' tends towards).

The examples I have conjured up above to illustrate this point are all extreme and mercifully - rare. In an attempt to emphasise this distinction between face and feelings concerning relationships, I now examine a trifling one. It occurred during a conference presentation which I gave some years ago. I began by apologising for the fact that my talk was going to be essentially the same one I had given at the conference of the same organisation the previous year. Anxious that no participants should be irritated by finding themselves listening to the same old stuff they had heard at that time, I assured any such people that they should feel free to get up and leave immediately and that if they did so I would not find it the least bit rude. At this point, one member of the audience, who had indeed been present at my talk the previous year, interjected with

\section{What makes you think we remember it?}

Through more-or-less conventional implicature, it could be inferred from this utterance that she herself did not remember the details of my talk the previous year and that probably any others in her position did not do so either, leading to the further inference that there was no need for me to apologise for the repetitive content of the upcoming talk.

In addition, still further inferences could be drawn. These concern the perlocutionary intent of the utterance. One, via a self-deprecating allusion to the speaker's powers of 


\section{Politeness across Cultures}

memory, was of reassurance that what I was about to say would be of interest. But the alternative, via an implicature that my talk the previous year had been singularly unmemorable, was of criticism that I am the kind of speaker who gives boring presentations. The interjector was (and is) a personal friend and occasional collaborator of mine. I was (and remain) perfectly confident that her intention was supportive. Consequently, I did not feel 'personally' attacked by her remark and my feelings suffered no damage whatsoever. However, aware of the possible latter interpretation, and aware that others were aware of it (a small ripple of laughter passed through the section of the audience who heard the remark), my face was attacked. In English language parlance, I was momentarily 'put out' and had to exercise a little poise in order to deflect the attack. Given the circumstances, this was easy to do. But to further emphasis the point that face and interpersonal affect are different, let us imagine that my interjector had actually had malign intent. Although this might have made it slightly more difficult for me to overcome the face attack, it still would have been possible for me to do so. I still could have behaved as if the intention of the remark was supportive. In this case, my face would have remained intact, even though my feelings would have been severely damaged.

In further support of the 'reality' of face, I now argue that it cannot it be equated to the management of personal reputation either. It may be argued that the reason for the mutual embarrassment in the extreme examples above, and the failure of any who are personally antipathetic to the victim to take advantage of his/her vulnerability, is that participants have their own faces to protect and therefore have to manage the impression of themselves given off to all others present. After all, few people wish to be thought heartless or cruel. There is of course much truth in this view. However, face as fellowinteractant-feeling seems to be more deeply ingrained than such instrumental considerations. We also do not wish to look heartless or cruel to ourselves, as in Goffman's (1967: 10) example of a person being "trapped by considerateness" into buying something they really don't want, even when there is no-one else around to witness the salesperson's defacement if we do not buy. Indeed, it is so pervasive that precisely the same empathetic reaction as above can often occur when we are not even present. For instance when watching a TV sitcom whose humour lies in awkward social situations, we sometimes find ourselves squirming, perhaps momentarily shielding our eyes from the screen or covering our ears even while we laugh. Our reactions, in other words, are those of extreme social discomfiture, despite the fact that we ourselves have no role in the social occasion. We behave as if our faces are at stake when our reputations cannot be. (This matter of face effects even when the faces affected are nowhere near the action raises analytical problems which I deal with in section 4 below. ${ }^{1}$

This section has argued in support of the use of the face-concept by attempting to show its conceptual and analytical independence from related aspects of (inter)personhood. However, its frequent use in scholarship over the last two decades, its 
success as a term which is sometimes bandied about rather loosely, carries it own dangers. The rest of this paper discusses the issues which have emerged thereby.

\section{What is the relation of face to (im)politeness?}

For historical reasons - mainly the fact that most of us were first drawn into the study of both via Brown \& Levinson (1987 [1978]) - face and politeness are routinely yoked together like some famous double act. (Indeed, a googlefight search returns as many entries for the hyphenated 'face-and-politeness' as it does for the unhyphenated version.) So I begin by stating the obvious. Face and politeness are not the same thing. They can't be, simply because one is a trait of interactants while the other is a trait of interaction. One is something interactants have, the other something they do.

In Brown \& Levinson - and commonly thereafter - the former is appealed to as an explanation for the latter. This is a perfectly feasible claim. However, the causal relationship between the two, especially when it is taken for granted, can mask a number of nuances. Arguably, face is not the only explanation for politeness (or, for that matter, impoliteness - see Culpeper, in press) and politeness is quite definitely not the only aspect of behaviour which face can explain. Goffman's original exposition (1967 [1955]) of facework amounts to some 12,000 words but contains only four instances of the lexeme 'polite(ness)', none of which attempts to define the lexeme or its relation to face. ${ }^{2}$

Moreover, to uphold the claim that people's faces cause them to be polite, it is necessary to assume either that politeness when it occurs is objectively identifiable ("Look, here is an instance of politeness") or that face is as salient a concept to interactants as politeness ("I am polite for reasons of face"). Neither assumption seems warranted. The former entails the adoption of a second-order approach to politeness (Watts et al 1992) which has come under increasing fire in the last decade or so by those (e.g. Eelen 2001, Watts 2003, Mills 2003, 2005) who advocate and practice a first-order approach ('politeness1', as it has come to be called) which focuses on subjective participant evaluations of what is and is not considered polite. Given the fact that the lexeme 'polite(ness)' is valueladen, that comparable (but not synonymous) lexemes exist in all cultures and that all these lexemes are salient to language users, there is much to be said for this approach.

The salience of the term 'face' as characterised above, on the other hand, appears to be very cross-culturally limited. Moreover, even where comparable lexemes are salient, they do not appear to capture quite the same phenomenon as that sketched above (see below). The term 'facework' is even less salient. For this reason, it seems to me that, in contrast to politeness, face lends itself more naturally to a second-order approach. Because Brown \& Levinson take such an approach and because a conception of face is the lynchpin of their model, it is probably more helpful to view their model as a theory of facework rather than of politeness (Watts 2003; Locher \& Watts 2005).

Thus face and politeness are distinct both substantively and methodologically. Clearly, there $i s$ a relation, but it is one of mutual hyponymy, not a causal one. Which is the hypo- 


\section{Politeness across Cultures}

nym and which the superordinate term is a matter of perspective. Seen from the inside, this paper places face in the superordinate position; that is, politeness is regarded as a (possible) aspect of facework. This relationship follows from the conception of politeness as culture-specific (as above) and face as pan-cultural (see immediately below). Seen from the outside, on the other hand, this paper can be seen as a discussion of one very important component of politeness, so that politeness is in the superordinate position and face in the hyponymic one.

\section{Face across cultures}

As suggested by my comments so far, the face that I am discussing in this paper is a second-order notion - a term that can be used by scholars from all over the world to denote the same concept whatever their origin or the specifics of their empirical application of it. This paper is not about the English lexeme 'face' or roughly equivalent lexemes in particular languages. It makes occasional reference to diverging, culture-specific instantiations, but it is not principally concerned with these. The focus is on the use of a universal parameter - a lens through which the divergences may be compared and better understood. Following Terkourafi (2007), I call this face2.

This is not to deny the value of studies of emic, culture-specific constructs instantiated by such lexemes (see, for example, Koutlaki 2002, Ruhi \& Istk-Guler 2007, Lim 2009, Ruhi 2009, Ukosakul 2009, Sifianou, this volume). As argued by Haugh (2009: 11-14) (and demonstrated by these studies), these can enrich our understanding of actual instances of interaction. But I take it as axiomatic that comparisons across cultures are more valid when we have a concept which is in itself culture-neutral; that is, what Terkourafi (2007) has termed a 'methodological abstraction' (see O'Driscoll 1996 for further argument to this effect). Such a concept also has the advantage that is does not require an essentialist conception of culture or of the extent of the influence of this or that culture on a person's interactive behaviour. In keeping with the argument expounded in the introduction to this volume, cultural norms are seen as just one possible contribution to this behaviour, the weight of which can vary from situation to situation (see section 8 below).

It might be argued that, in order to avoid confusion between first-order and secondorder perspectives on face, a term should be found for the latter which is transparently, exclusively technical (i.e. not salient in any culture). The fact that the English lexeme 'face' and its equivalents in other languages play a role, albeit usually a minor one, in everyday usage might therefore make it an unsuitable candidate. However, quite apart from the difficulty of persuading all researchers to recognise and adopt such a term, employing one which has reflexes in everyday usage actually has an advantage. It helps us to guard against our research straying too far from everyday experience. It can also suggest nuances and conceptualisations that we might otherwise miss (I offer one such example below). I therefore think it advisable to stay with the term 'face' for the second- 
order notion. When the possibility of confusion with the first-order notion arises, it is only necessary to specify 'face 2 '.

\section{When can face be relevant?}

This is a question about the range of communicative behaviour to which the concept might be applied. As the English language lexeme suggests, face and facework prototypically pertain to face-to-face interaction. It is, after all, only when people are visibly in each other's presence that the kinds of face effects discussed in section 1 above can occur. It is also fairly clear that it was this kind of interaction which Goffman had in mind in his exposition of the concept; notwithstanding his remark, two-thirds of the way through his exposition, that "most of what has been said so far applies to encounters of both an immediate and mediated kind", all his exemplification assumes face-to-face encounters and anyway it is "during direct personal contact" that "the significance of face becomes especially clear" (Goffman 1967: 33). ${ }^{3}$

This conception of face - as operational in face-to-face interaction - leads to one deduction and one problem. The deduction is that people do not have faces in the way that they have legs or bicycles. People have the latter whether or not they are walking or pedalling. But people have faces only when they are interacting. Face is "constructed discursively with other [interactants]" and is thus "attributed in each individual instance of interaction" (Locher \& Watts 2005: 12). Such a limitation is, of course, implicit in line 4 of Goffman's definition and in his oft-quoted statement that a person's face is "on loan to him from society" (Goffman 1967: 10) ${ }^{4}$

This limitation to interaction does not, of course, mean that we interactants enter each encounter with entirely blank faces. We carry around with us the building blocks of face construction (see below) outside interaction, all of which have their own histories. As a result, a person's face in the present encounter usually has a connection with his/face in previous encounters (especially those with the same interlocutors), with the noninteractive background to the present encounter and indeed his/her more general noninteractive experience, so that a full exploration of the nature of his/her face in the present encounter may often need to take these factors into account. (See Haugh 2009: 11-12 and Spencer-Oatey 2009: 137-138 \& 151-152 for calls to this effect; see Sifianou in this volume for a considered argument.) These elements and factors all have some sort of bearing on face.

Nevertheless, I would argue that these building blocks get assembled, albeit in a microsecond, only in interaction (see Terkourafi 2005: 248-249; also Goffman 1967: 7-8). It seems to me that this restriction on the potential relevance of face is a necessary one. Without it, it becomes difficult to separate the concept of face from that of self-image (i.e. the set of ideas which a person has about him/herself and would like other people to have) or reputation (i.e. the image that other people have of this person when they happen to call him/her to mind) or identity (i.e. images that other people have when calling this type 


\section{Politeness across Cultures}

of person to mind). It may be argued that face can still be a useful term for the aggregate of these characterisations about a person. However, section 1 above has indicated that in interaction things can happen which none of these terms nor their aggregate can capture. Without this limitation, we lose sight of the immediacy of face as illustrated above.

But it is the insistence of face as a feature manifest in face-to-face interaction which raises a problem. Despite the above considerations, the concept of face is now frequently, and convincingly, used in studies of interpersonal aspects of communication between people who cannot see each other's faces at the time. Examples include studies of telephone communication (e.g. Sifianou 1989, Economidou-Kogetsidis 2005, MarquezReiter 2005, 2009), radio-talk (e.g. Ferenčík 2007), conventional written communication (e.g. many of the contributions in Culpeper \& Kadar 2010), e-mail encounters (Davies et al 2007, Merrison et al, in prep.) and other kinds of computer-mediated communication (e.g. Pizziconi 2007) and even published scientific articles, where, therefore, most readers are unidentified and potentially unrestricted (Myers 1989, Koutsantoni 2004).

In these types of communication, the interdependent and situated characteristics of face noted above seem to be missing. What the producer says or writes may be extremely hurtful or pleasing to one or more receivers. It may present the producer in a very unflattering light or divulge information which is damaging to the reputation of one or more of the receivers. But in all such cases, I would argue that participants' faces remain untouched at the time because there are no faces on the scene.

This lack of face engagement is even more obvious in written communication, when production and reception of messages are dislocated not only in space but also in time (so that it becomes problematical to pinpoint exactly when the 'interaction' - if that is what it is - is going on). In these cases, the producer is not present to witness the reception of a message and so receivers do not have to manage their reception of it (and the producer, aware of this, does not have to take such immediate reception into account when composing it - hence the ubiquitous modern tendency to ill-judged e-mail messages which turn out to cause offence).

It may be thought at this point that I am confusing the purportedly second-order concept which is the focus of this paper with a very literal denotation of the English lexeme (therefore first-order) 'face'. And certainly even in a rather impersonal form of dislocated communication such as this paper, I am performing self-presentation. Indeed, I am taking a lot of care to present myself as the possessor of relevant positive attributes, as someone whose arguments are interesting, well-expressed and convincing,. Both my self-image and reputation are at stake. But my face isn't (at least not right now - see below). It has taken me about an hour to compose this paragraph. Were I to take even a quarter of that time to make the same points in a face-to-face encounter, my claim to two of the above positive attributes would be shot to pieces. And if at this point you throw up your hands in a gesture of irritation, sneer and shout "rubbish", it doesn't touch my face because I don't know you're doing it. If you then proceed to broadcast this negative opinion to rel- 
evant colleagues, including me, I will feel downcast, deflated and perhaps hurt. And if you express this opinion convincingly, my self-confidence will take a severe dent. But until I meet you and/or these colleagues, there are no face-effects.

In addition, there is actually only a narrow bandwidth of my self-image and reputation at stake right now. Face presents an image of the whole person. In face-to-face interaction

on the basis of a few known attributes, [a person] is given the responsibility of possessing a vast number of others. His coparticipants are not likely to be conscious of the character of many of these attributes until he acts perceptibly in such a way as to discredit his possession of them [Goffman 1967: 7]

In the present circumstances I do not have this responsibility. I am wearing an old dressing-gown, I am unshaven and I have just picked my nose. But you are not here to perceive any of this.

Given these observations, we need to ask how face can be relevant to dislocated communication. In what sense(s) can it be valid to refer to face, as so many studies have done, when analysing instances of this kind of communication? I have two answers. The first is to advance the face-to-face encounter as our human prototype for communication, with which, therefore, we habitually frame all kinds of communication and which therefore influences our behaviour even in dislocated communication. (Some such metaphorical extension seems to be going on in our reactions to sitcom situations noted above.) Notwithstanding the conceptual distinction argued above between face and feelings of selfworth, it is undeniable that the two are closely related. In most cases, damage or enhancement of our faces tends to lead to damage or enhancement to our sense of selfworth (Goffman 1967: 6). Now, because these kinds of feelings are operative regardless of the mode of communication, it is quite possible that we habitually behave with an eye to our faces in all modes, that we project them onto page or screen or into the mouthpiece.

In support of the feasibility of this view, we may note that until the advent of telecommunications and mass literacy - both very recent indeed in the sweep of human history - face-to-face was the only direct means of linguistic communication available to the vast majority of people. Perhaps, therefore, we humans are hard wired for face-to-face interaction and thus carry over its features into all kinds of communication. Certainly, when talking on the phone, we tend to use many of the same facial expressions and physical gestures as when we are physically present to our interlocutors. Moreover, it is only through the assumption that dislocated communication is felt almost as immediately as face-to-face interaction that we can make sense of recent concerns in the media about 'cyber bullying'.

However, there is a limit to this answer. It remains easier to lie over the phone than it is face-to-face (and this is just one reason why so many have misgivings about the prospect of video phones). And other kinds of dislocated communication do not exhibit those 


\section{Politeness across Cultures}

physical symbols of the face-to-face mode. Moreover, the face-to-face-as-prototype answer is based on an explanation of our communicative behaviour but says nothing about face effects. An additional defence of studies employing the concept of face in the analysis of dislocated communication is therefore required. It lies in 'the future'; that is, in the mutual awareness of participants that there is at least a possibility - however remote - that they will meet face-to-face at some time hence. The result of this possibility is that while such communicants do not have faces at the time, what transpires is likely to have consequences for their future faces. Aware of this, participants in dislocated communication take these into account and face becomes salient. The more likely future face-to-face contact, the more salient face will be.

The point remains, however, that no acts performed in writing can be directly face damaging or face-enhancing for the simple reason that (I repeat) there are no faces involved. They can be face-threatening only in the sense that they may impact on future face-to-face contact. (See Goffman 1967: 7-8 and O'Driscoll 2007a: 240-242 for similar presentations of future face consequences.) In the study of dislocated communication, therefore, it is more meaningful to employ face in the analysis of the producer's language and his/her intentions than it is to employ it in any estimation of actual face effects.

\section{When and how much is face actually relevant?}

This is a question of the explanatory value of the concept of face for the analyst when $\mathrm{s} /$ he considers instances of interaction. Just as I have argued the people do not strictly have faces when they are not interacting face-to-face, so for the same reason people always have faces when they are. By definition, therefore, face is always potentially relevant in any such interaction. It is always 'immanent' Tracy (1992).

However, it is plain that sometimes it matters an awful lot and sometimes it matters hardly at all. There have been arguments that some interactive behaviour is better explained by other means. For instance, there are situations when desire for clarity and/or attention to the impersonal task at hand is all-consuming. Some of those put forward by Brown \& Levinson (1987: 94-98) to explain 'bald on record' utterances fall into this category. And certainly a recurrent thread of this paper is that it is wise not to try to make face do too much analytical work. This is a point made by Spencer-Oatey (2009), who offers examples of other interactional goals being pursued regardless (even in spite of) face.

Another kind of argument is to advance culture-specific values as impacting on the amount of salience accorded face (and therefore on its explanatory value). Hill et al's (1986) much-followed notion of 'discernment', which purportedly takes precedence over face in Japanese society, is one such example. Another (apparently contradictory) example is the view that 'the east' values face over objective truth while 'the west' does the opposite (see, for example. Goffman 1867: 17, ftnt.). However, whether such values can in themselves affect the amount of importance given to face is doubtful (see O'Driscoll 
2007b: 470 and 2010: 274-275 for arguments against the discernment view). It is in the nature of face as conceived in this paper that it is not dependent on such values. At the same time, however, it is consistent with this conception to expect the significance of face to vary cross-culturally - not in the general sense of overall interactional ethos implied above but rather with respect to specific types of situation.

One observable divergence concerns how comparable encounters are framed. The notions of occasion (Goffman 1963: 18-21), activity type (Levinson 1979) and speech event (Hymes 1972) are all broadly similar in that they allow for subjectively and culturally influenced responses to the question: what sort of thing is going on here? Divergent answers to this question will produce frames which bring face more or less to the fore. For example, my personal experience and observation suggests that default behaviour in certain kinds of podium event in Belgian culture (such as public $\mathrm{PhD}$ defences, the introducing of guest speakers to an audience or political debates on TV) highlight face, by addressing the main actors directly as 'you', much more than they do in British culture, which downplays the significance of face by avoiding 'you' in such situations. (See O'Driscoll 2007b: 483-484 for a similar example.)

Another attested divergence is in the face significance attached to particular speech acts. For example, Thomas (1983) and Smith (1985) offer examples in which a westerner objects to the expectation that they should proffer an apology, on the grounds that this is a personal admission of fault which therefore impacts negatively on their faces, whereas we are told that in the cultural milieu it is a mere formality and carries no such face damage.

Other aspects of variability in face-salience are culture-neutral. One such aspect which may be tentatively advanced as applying in all cultures pertains to participant relationships. Following Wolfson (1983), who observed what she called the 'bulge' in address forms and other aspects of interpersonal behaviour, it can be suggested that face is always likely to be more salient in interaction with people who are neither strangers nor intimates than with people who are. Additional variables suggested by O'Driscoll (2007a: 252-253) are numbers of participants and relative predictability of the encounter; all else being equal, the greater this number and the less expected the encounter, the more face will be at stake.

\section{Lexico-grammatical considerations}

Lurking behind attempts to answer the questions asked in other sections of this paper and potentially befuddling discussion of them - are a number of lexico-grammatical issues. In order to facilitate discussion on the face concept and its application to the study in instances of interaction, I suggest we need to be clear each time we use the term about the following:

\subsection{Positive attribute versus existential attribute}


In other words, are we using the term to denote a desideratum of interactants or to denote something which they have anyway but which can very in quality? The most common expression in everyday modern English containing the lexeme is probably 'lose face', which indicates the former. Other expressions used in the scholarly literature such as 'give face', 'gain face' and 'claim face' similarly present face as a value-laden term, denoting a trait of which people can be divested, or have more or less of, during interaction. Other collocations, on the other hand (e.g. damage face, enhance face, boost face), tend to present face as something mutable but ineradicable (i.e. existential attribute). Still others (e.g. threaten face) could be interpreted as of either type.

Goffman himself allows for both interpretations. He distinguishes early on in his essay (Goffman 1967: 8) between a state of being 'out of face' (i.e. face as positive attribute) and that of being in the 'wrong face' (i.e. existential attribute). Immediately thereafter, however (Goffman 1967: 8-9), he describes either state as possibly leading to being 'shamefaced' (the state portrayed in section 1 above) and proceeds to remark that in modern English 'lose face' can apparently refer to any three of these states and 'save face' to any actions taken to repair or avoid any of the three. Subsequently, he makes no explicit distinction between the results of being 'out of face' or in the 'wrong face' (i.e. they are nearly always mentioned together). In other words, Goffman is not much help in this matter.

I do not wish to suggest that we as scholars must arrive at a decision as to which conception of face we should follow. I only wish to enjoin us, for the sake of avoiding possible misinterpretation, to be clear about which of these two senses of face we mean whenever we use the term. As indicated above, my own preference is for face-as-existentialattribute, as something whose quality can be threatened in interaction but whose existence cannot. From this viewpoint, collocations such as losing face, gaining face or giving face refer only metaphorically to the dispossession, repossession or acquisition of face and are understood to denote various kinds of change in the quality of face (in the same way that in English, talk of a person 'losing his/her reputation' is understood to mean a change from a good reputation to a bad reputation). However, it may be that there is room for the face-as-positive attribute conception as well, in the sense that some kinds of people in some kinds of situation, for example very young children among adults, are often presumed not to have any kind of face at all.

\subsection{Temporal perspective}

It is possible to analyse a moment of interaction from a before-perspective or an afterperspective. If we take the former, we are focused on producer intentions and so will naturally refer to face-wants, face-threats and efforts to avoid such threats or mitigate their potential effects (as in Brown \& Levinson's scheme). But if we take the latter perspective, we are focused on receivers and actual effects. This is what the discursive approach mentioned above does. In such cases, it makes more sense to talk about face-damage (rather 
than threat) and repair work (rather than mitigation). Phrases such as face-saving and face-attack can refer to either perspective; that is, as attempt or as achievement.

\subsection{Mass versus count noun}

In other words, are we using the term to denote face the phenomenon of interaction or its myriad instantiations interactants at any one time? The distinction to be made here is similar to that between (uncountable) language as a biological human phenomenon and (countable) languages as social creations. So far, as indicated in the section headings above, the discussion has been centred on various aspects of face-the-phenomenon and it has been suggested that face is an existentially inevitable trait of interactants (by virtue of them entering into interaction). But included in the discussion have been references to people's faces (plural) on the assumption that the precise nature of the face of any one person in any one instance of interaction can vary and be distinct from that of other interactants and that in other instances of interaction. The section headings below refer to faces (plural) because they address questions of how this variation and distinctness may be described.

The effort in sections 8 and 9 below is to discuss the construction and composition of individual faces in instances of interaction. In the course of this effort, reference is sometimes made to cross-cultural variation in the conceptualisation of face-the-phenomenon, but it needs to be stressed that this kind of variation, being a first-order matter, is not the focus of the discussion. Rather, the attempt is to explore variation from a face 2 perspective, in which, therefore, the variability arises not from divergent conceptualisations but from varying proportions of the suggested universally available building blocks (section 8) of face and different degrees of salience of various possible aspects of face (to which cross-culturally divergent values are just one contributory factor). But before that, it is necessary to raise one more very basic question.

\section{To who or what do faces pertain?}

In the discussion so far, it has been assumed that faces belong to interacting individuals. In reaction to the individualist (usually qualified as 'western', sometimes characterised as 'self-obsessed') orientation that they perceive as thereby implied, some researchers have questioned this assumption. Two alternatives have been offered. One is the notion of group face (e.g. Nwoye 1992, De Kadt 1998), introduced to account for the fact that many cultures subscribe to a collectivist orientation to identity, so that the 'self' with which face is connected may better be described as pertaining to a relevant social group. Goffman hints at this possibility when, immediately following his definition of face, he adds the face is "an image [of self] that others may share, as when a person makes a good showing for his profession or religion by making a good showing for himself". And in- 
deed, as Sifianou demonstrates in this volume, one does not have to be a 'collectivist' to feel the face effects of the actions of others who are not present.

The notion of group face is not a refutation of the conception of face as residing with the individual, but simply an argument that it does not entirely do so. The second alternative, however, attempts a blanket refutation. It regards Goffman's conception as peculiarly western (e.g. Bargiela-Chiappini 2003:1463) and therefore unsuited as a cultureneutral one (i.e. face2). As an alternative, Arundale (2006, 2009) proposes 'faceconstituting theory', in which "face is not an individual possession" (Arundale 2009: 38) but rather "a relational phenomenon [which] arises in the dialectic interplay between what is individual and what is social" (Arundale 2009: 43).

In its emphasis on face achieved within interaction, as an effect rather than a cause of moves in interaction, and therefore in continual flux during interaction, Arundale's view reflects the picture painted in the first section above and is in accord with the argument in section 4 above that face exists only in interaction. However, I cannot myself see any inconsistency in accepting this view but nevertheless locating faces (plural) firmly as pertaining to individual interactants. This is not to deny their interdependence or their mutability. It is just that I find it difficult to see how, practically and meaningfully, we could find a way to describe the nature or quality of 'the face' (singular) of a plurality of interactants. Nor is it to deny the existence of collectivist or even holistic (Lim 2009) orientations in some cultures, resulting in interactional behaviour that is intimately concerned with the self-image(s) of the group(s) which an interactant is taken to represent. But I would regard this orientation simply as affecting the balance of ingredients contributing to a (singular) person's face (see below).

I $d o$, conversely, see a problem with notion of group face, stemming from the simple observation that it is very rare indeed for two or more whole groups (that is, all their members) to participate in the same encounter. And yet if face exists only in interaction, such a condition would be necessary for 'group face' to have meaning 5 . Without it, the term 'face' extends beyond interaction, so that 'face' and 'reputation' or 'self-image' become essentially synonymous.

This issue is not closed. But having nailed my colours to the mast in this respect, I assume in the remaining sections below that faces belong to individuals.

\section{What are faces made from?}

This is a question about the elements contributing to an interactant's face at any one time, about the inputs to that face. I propose that all of the following building blocks can contribute, though in varying proportions.

\subsection{Personal wants regarding self-image}

The face-as-wants approach is Brown \& Levinson's truncation of Goffman's definition. It ignores lines 3 and 4 and arguably downplays the "effectively" in line 2 as well (see 
O'Driscoll 2007b: 467-468). Nevertheless, it is clear that how we would like to be seen by others has an effect on how we will be seen because it influences our behaviour. In some respects, we have clear conscious choices in this matter. We can, for example, pick and choose what clothes to wear because we know that our decision will effect the faces we will later be given. In other respects, there is little if any consciousness involved and our interactive behaviour is simply a reflection of our own self-images and/or a compulsion to behave in a certain manner. But neither a lack of self-awareness nor the undoubted influence of social norms, sometimes very strong, are in themselves refutations of the contribution of personal wants (O'Driscoll 2010: 274-275). Likewise, the fact that there are severe methodological problems in estimating how such unobservable phenomena actually play out in interaction (Arundale 2006: 199) is no excuse for denying their existence.

\subsection{Ascribed characteristics}

I have in mind here the usual social identity variables such as age, gender, ethnicity, occupation and geographical provenance, as well as evident physical characteristics. Clearly, if I find myself identified by others in interaction as a large, elderly, male, British/Irish academic from London, certain behavioural expectations are conferred upon me which can be difficult to wriggle out of. They constitute part of the 'line' I am assumed to be taking. I have suggested above (section 7) that this ingredient will make a larger contribution for members of collectivist cultures than it would for members of more individualistic ones.

\subsection{Personal reputation}

Even people we have never met before have often heard about us, so that frequently we enter into interaction with our own histories having already arrived. As a result, with all except complete strangers, the line which we are assumed to be taking, in addition to the typological characteristics above, involves personal ones such as early riser, friendly, honest, untidy and so on. It is this contributor to face 2 which seems to be emphasised, albeit with a significant admixture of ascribed characteristics, in lexemes approximating to the English 'face' (i.e. face1) in some east Asian cultures. (See, for example, Lim \& Choi 1996 for Korean culture, Gao 2009 for Chinese and Ukosakul 2009 for Thai).

\subsection{Interpersonal history}

This contributor applies to all but only encounters between people who have had dealings on previous occasions. If they have met on many occasions and have 'a relationship', 


\section{Politeness across Cultures}

they will have developed certain habits of interaction which emphasise certain aspects of their faces. But even if they met just once before, a particularly memorable encounter will have its effects the next time they meet. (Hadfield \& Hahn's covenant face - see section 8 below - derived with reference to Korean culture, adds this element to the construal of face1 mentioned in the previous paragraph. See Sifianou in this volume for a fuller account of this contributor)

\subsection{Culture}

It is well-known that cultural background involves certain values and norms of behaviour in interaction which induce certain habits and expectations among interactants. It is divergences between those of one culture and those of another, of course, which have been appealed to in innumerable studies of interaction across cultures and cross-cultural comparisons. Sometimes, these divergences pertain directly to interaction, such as the historical Chinese norm of self-denigration and other-elevation (see, for example, Kádár 2010). In section 5 above, it was suggested that divergent conceptions of speech acts and activity types can affect the degree of salience of face. But these can also, of course, affect which aspects of face are presumed to be important (see O'Driscoll 2007b: 475-477 for a simple example). And sometimes, the divergences also involve values not directly pertaining to interaction themselves but nevertheless having a crucial affect upon it (see Ting-Toomey 2009: 236-242 for a recent example).

\subsection{Situation}

Here, I have in mind all those elements listed in Hymes' (1972) famous SPEAKING mnemonic. I have left this contributor until last because I suspect it is the most important. This follows from the conception of face as co-constructed within interaction. Indeed it might be thought that, if face only exists in interaction and interactants' faces emerge as their joint accomplishment (Arundale 2006), the unfolding situation encompasses all that contributes to them. However, as Haugh (2009: 5-12) reminds, face is not only coconstituted in interaction but also constitutive of it. All situations of interaction are subject to historical influences. The other contributors listed in this section are, in effect, an attempt to itemise these.

The crucial role of situation, I suggest, lies in the fact that it influences strongly the relative weights accorded to the other ingredients. In Goffman's words:

During a contact of a particular type, an interactant.... can expect to be sustained in a particular face ... Given his attributes and the conventionalized nature of the encounter, he will find a small choice of lines will be open to him and a small choice of faces will be waiting for him.

[Goffman 1967:7] 
Different elements of situation thrust different building blocks to the fore or consign them to the background. For example, if the ascribed identities of participants differ in salient ways, the salient characteristic(s) can become a major contributor to faces. (See O'Driscoll 2001 for an example concerning ethnolinguistic identity.) Conversely, if two people with a long and strong interpersonal history find themselves interacting among several others who are not privy to that history, this factor will become a much less important contributor to their faces than if they were alone together.

But in truth I suspect that all these building blocks can affect each other, which is why the construction of faces is such a complicated matter. Arguably, one might regard situation as the origin and all the others as derivative. Or perhaps one might encapsulate all of them in a combination of situation and culture. At any rate, the relative weight to be accorded situation and culture in the construction of faces is a topic that needs more research

\section{What are faces made of?}

What are the facets of faces? How do we actually talk about a person's face in interaction? Can we identify an X,Y, Z, N face at any one time? Goffman's exposition is entirely lacking in any specification of the (cross-situational, relatively permanent) constituents of face; that is, the "social attributes" in terms of which, according to him, face is "delineated" (Goffman 1967: 5). This absence is perhaps inevitable given his definition of face as radically situationally contingent (line 4), as this could be taken to imply that the total configuration of constituents will be somewhat different in every single instance of interaction.

However, the scary possibility that there are as many faces as there are encountertimes-participants has not deterred researchers from attempting to identify specific types and/or instantiations of face. The most well-known attempt is that of Brown \& Levinson (1978), who posit just two types: positive and negative. Notwithstanding the widespread cross-cultural criticism of both the applicability of these facets (in particular the latter) and their conceptualisation, they have proved remarkably durable in scholarship. A number of recent works have advanced what are effectively revised conceptions of them. Arundale (2006) and Terkourafi (2007) see them (albeit under different labels and radically different etiologies) as universal abstract concepts from which all visible, actual faces in particular cultures and situations can ultimately be derived. O'Driscoll (2007b), on the other hand, sees them as comprising just one dimension of face which is constant across cultures and situations (though with greatly varying degrees of salience). Bravo (2008) suggests something in between these poles. .

The implication of the one-dimensional view of positive and negative is that there are other facets to faces. This position has been argued on the grounds that B\&L's positive and negative are both too grossly defined and just don't cover enough grounds to capture the range of face concerns (e.g. Tracy \& Baratz 1994: 290-291.) And indeed, other kinds 
of face have been proposed. Some are straightforward additions to positive and negative, designed to account for phenomena which these facets seem unable to encompass (e.g. Lim \& Bowers' 1991 competence face, O’Driscoll's 1996 culture-specific face, Hadfield \& Hahn's 2007 covenant face). Other suggestions are more sweeping. They include the purportedly universally available inventory offered by Ting-Toomey (2005; see also 2009: 240), the list of culture-specific elements outlined by Mao (1994) and the series of face dimensions along each of which there can be certain 'settings' (Spencer-Oatey 2005).

While there is not necessarily any value in attempting to establish an agreed list of types of face, more research in this field, into how we can principally go about describing the nature of faces at any one moment, would be valuable.

\section{Final word}

As warned at the start, this paper is very far from comprehensive. A number of worthwhile issues have not been discussed (for example the issue of exactly how faces change during interaction and that of self-face versus other-face). To finish, here is a very tentative, and somewhat whimsical, suggestion. To capture the notion of faces being constructed from several elements (their composite nature), and the relation between the elements and the construction, and the mutability of faces, and the fact that face is essentially a surface phenomenon (and thus different from self-image, self-esteem and other inner feelings of self-worth), I would like to advance the cosmetic metaphor of face make-up as a way of describing a person's face at any one time. A person can choose what to put on (the personal wants element), from what is generally acceptable (the culture element), what is more particularly expected for his/her kind of person (the ascribed characteristic element) and what is actually available at the time (the situation element). Note also that there are lingering after-effects of make-up (it doesn't come off so easily the personal reputation and interpersonal history elements).

This metaphor probably gives too much emphasis to pre-interactive decision-making for it to have much value. We would have to see people as applying make up to each other during interaction - in this cosmetic universe, people get together and routinely apply make-up to each other. But the notion of make-up is at least a way of emphasising that a person's face is a composite.

\section{References:}

Arundale, R.B. (2006) 'Face as relational and interactional: A communication framework for research on face, facework, and politeness', in Journal of Politeness Research, 2 (2), pp. 193-216.

Arundale, Robert B. (2009) 'Face as emergent in interpersonal communication: an alternative to Goffman', in Bargiela Chiappini \& Haugh (eds.) pp. 33-54. 
Bargiela-Chiappini, F. (2003) 'Face and politeness: new (insights) for old (concepts)', in Journal of Pragmatics, 35 (10-11), pp. 1453-1469.

Bargiela Chiappini, F., and Haugh, M. (eds. 2009) Face, Communication and Social Interaction, London, Equinox.

Bravo, D. (2008) '(Im)politeness in Spanish-speaking socio-cultural context: introduction', in Pragmatics, 18, pp. 563-576.

Brown, P., and Levinson, S.C. (1987 [1978]) Politeness: Some Universals in Language Usage, Cambridge, Cambridge University Press. (Main body of which first published in E. Goody (ed.) Questions and Politeness, Cambridge, Cambridge University Press.)

Culpeper, J. (in press) Impoliteness: Using Language to Cause Offence, Cambridge University Press

Culpeper, J., Kádár, D.Z. (eds. 2010) Historical (Im)politeness, Berne, Peter Lang.

Davies, B.L., Merrison, A.J., and Goddard, A. (2007) 'Institutional apologies in UK higher education: Getting back into the black before going into the red', in Journal of Politeness Research, 3 (1), pp. 39-63.

De Kadt, E. (1998) 'The concept of face and its applicability to the Zulu language', in Journal of Pragmatics, 29, pp. 173-191.

Economidou-Kogetsidis, M. (2005) "Yes, tell me please, what time is the midday flight from Athens arriving?': Telephone service encounter and politeness', in Intercultural Pragmatics, 2/3, pp. 253-273.

Eelen, G, (2001) A Critique of Politeness Theories, Manchester, St Jerome.

Ferenčík, M. (2007) 'Exercising politeness: membership categorization in a radio phonein programme', in Pragmatics, 17/3, pp. 351-370.

Gao, G. (2009) 'Face and self in Chinese communication', in Bargiela-Chiappini and Haugh (eds.) pp. 175-191.

Goffman, E. (1964) 'The neglected situation', in American Anthropologist, 66/6, Part II (Special Issue), pp. 133-136.

Goffman, E. (1967 [1955]) 'On Face-Work', in E. Goffman (collection), Interaction Ritual: Essays on Face-to-Face Behavior, Harmondsworth, Penguin, pp. 5-45. (Originally in Psychiatry: Journal for the Study of Interpersonal Processes, 18 (3), pp. 213-231).

Goffman, E. (1981) Forms of Talk, Oxford, Blackwell.

Grice, H.P. (1975) 'Logic and conversation', in Cole, P., and Morgan, J.L. (eds.) Speech Acts, Syntax and Semantics, Vol. Ill: Speech Acts, New York, Academic Press, pp. 41-58.

Hadfield, H., and Hahn, J.-W. (2007) Concepts of Face and Korean Apologies, Unpublished Manuscript downloaded January 7, 2010, from <http://www2.hawaii.edu/ hunterh/Docs/FaceAndKoreanApologies.pdf> . 


\section{Politeness across Cultures}

Haugh, M. (2009) 'Face and interaction', in Bargiela-Chiappini and Haugh (eds.) pp. 130.

Hill, B., Ide, S., Ikuta, S., Kawasaki, A., and Ogino, T. (1986) 'Universals of linguistic politeness: Quantitative evidence from Japanese and American English', in Journal of Pragmatics, 10, pp. 347-371.

Hymes, D. (1972) 'Models of the interaction of language and social life', in Gumperz, John, and Hymes, D. (eds.) Directions in Sociolinguistics: The Ethnography of Communication, New York, Holt, Rinehart \& Winston, pp. 38-71.

Kádár, D.Z. (2010) 'Exploring the historical Chinese polite denigration/elevation phenomenon', in Culpeper and Kádár (eds.), pp. 119-145.

Koutsantoni, D. (2004) 'Certainty across cultures: A comparison of the degree ofcertainty expressed by Greek and English speaking scientific authors', in Intercultural Pragmatics, 2/2, pp. 121-149.

Levinson, S.C. ([1979] 1992) 'Activity types and language', in Drew, P., and Heritage, J. (eds.) Talk at Work, Cambridge, Cambridge University Press, pp. 66-100 (originally in Linguistics, 17, pp. 365-399.)

Lim, T.-S. (2009) 'Face in the holistic and relativistic society', in Bargiela-Chiappini and Haugh (eds.) pp. 250-268.

Lim, T.-Seop, and Bowers, J.W. (1991) 'Facework: solidarity, approbation, and tact', in Human Communication Research, 17/3, pp. 415-450.

Lim, T.-S., and Soo H.C. (1996) 'Interpersonal relationships in Korea', in Gudykunst, W.B., Ting-Toomey, S., and Nishida, T. (eds.) Communication in Personal Relationships across Cultures, Sage Publications, Thousand Oaks, CA, pp. 122-136.

Locher, M.A., and Watts, R.J. (2005) 'Politeness theory and relational work', in Journal of Politeness Research, 1/1, pp. 9-33.

Mao, LM. (1994) 'Beyond politeness theory: 'Face' revisited and renewed', in Journal of Pragmatics, 21, pp. 451-486.

Marquez Reiter, R. (2005) 'Complaint calls to a caregiver service company: The case of desahogo', in Intercultural Pragmatics, 2/4, pp. 481-514.

Marquez-Reiter, R. (2009) 'How to get rid of a telemarketing agent? Facework strategies in an intercultural service call', in Bargiela-Chiappini and Haugh (eds.) pp. 55-77

Merrison, A., Haugh, M., Davies, B.L., and Wilson, J.J. (in preparation) 'Getting stuff done: Comparing 'e-mail requests' from students in higher education in Britain and Australia', Special issue on "Im/politeness across Englishes" for Journal of Pragmatics.

Mills, S. (2003) Gender and Politeness, Cambridge, Cambridge University Press.

Mills, S. (2005) 'Gender and impoliteness', in Journal of Politeness Research, 1 (2), pp. 263-280.

Myers, G. (1989) 'The pragmatics of politeness in scientific articles', in Applied Linguistics, 10, pp. 1-35. 
Nwoye, O.G. (1992) 'Linguistic politeness and sociocultural variation of the notion of face', in Journal of Pragmatics, 18 (4), pp. 309-328.

O'Driscoll, J. (1996) 'About face: A defence and elaboration of universal dualism', in Journal of Pragmatics, 25, pp. 1-32.

O’Driscoll, J. (2001) 'A face model of language choice', in Multilingua, 20 (3), pp. 245268.

O'Driscoll, J. (2007a) 'What's in an FTA? Reflections on a chance meeting with Claudine', in Journal of Politeness Research, 3/2, pp. 243-268.

O'Driscoll, J. (2007b) 'Brown \& Levinson's face: how it can - and can't - help us to understand interaction across cultures', in Intercultural Pragmatics, 4/4, pp. 463-492.

O’Driscoll, J. (2010) 'Epilogue', in Culpeper and Kádár (eds.), pp. 267-289.

Terkourafi, M. (2005) 'Beyond the micro-level in politeness research', in Journal of Politeness Research, 1 (2), pp. 237-262.

Terkourafi, M. (2007) 'Toward a universal notion of face for a universal notion of cooperation', in Kecskés, I., and Horn, L. (eds.) Explorations in Pragmatics: Linguistic, Cognitive and Intercultural aspects, Mouton Series in Pragmatics 1, Berlin, Mouton de Gruyter, pp. 307-338.

Pizziconi, B. (2007) 'Facework and multiple selves in apologetic metapragmatic comments in Japanese', in Bublitz, W., and Huebler, A. (eds.) Metapragmatics in Use, Amsterdam, John Benjamin, pp 49-72.

Ruhi, Ş. (2009) 'Evoking face in self and other presentation in Turkish', in BargielaChiappini and Haugh (eds.) pp. 155-174.

Ruhi, Ş., and Iştk-Güler, H. (2007) 'Conceptualising face and relational work in (im)politeness: revelations from politeness lexemes and idioms in Turkish', in Journal of Pragmatics, 39, pp. 681-711.

Sifianou, M. (1989) 'On the telephone again! Differences in telephone behaviour: England versus Greece', in Language and Society, 18, pp. 527-544.

Spencer-Oatey, H. (2005) '(Im)politeness, face and perceptions of rapport: Unpackaging their bases and interrelationships', in Journal of Politeness Research, 1(1), pp. 95119.

Spencer-Oatey, H. (2009) 'Face, identity and interactional goals', in Bargiela-Chiappini and Haugh (eds.) pp. 137-154.

Smith, L. (1985) 'EIL versus ESL/EFL: What's the difference and what difference does the difference make?', English Teaching Forum, 23/4, pp. 2-6.

Ting-Toomey, S. (2005) 'The matrix of face: an updated face negotiation theory', in Gudykunst, W.B. (ed.) Theorizing about Intercultural Communication, London, Sage, pp. 71-92.

Ting-Toomey, S. (2009) 'Facework collision in intercultural communication', in Bargiela-Chiappini and Haugh (eds.) pp. 227-249. 
Thomas, J. (1983) 'Cross-cultural pragmatic failure', in Applied Linguistics, 4(2), pp. 91112.

Tracy, K. (1992) 'The many faces of facework', in Giles, H., and Robinson, P. (eds.) Handbook of Language and Social Psychology, Chichester, Wiley, pp- 209-226.

Tracy, K., and Baratz, S. (1994) 'The case for case studies of facework', in Ting-Toomey, Stella (ed.) The Challenge of Facework, Albany, State University of New York, pp. 287-305.

Ukasakol, M. (2009) 'The significance of 'face' and politeness in social interaction as revealed through Thai 'face' idioms', in Bargiela-Chiappini and Haugh (eds.) pp. 289-305

Watts, R.J. (2003) Politeness, Cambridge, Cambridge University Press

Watts, R.J., Ide, S., and Ehlich, K. (1992) 'Introduction', in Watts, Ide, Ehlich (eds.) Politeness in Language: Studies in its History, Theory and Practice, Berlin and New York, Mouton de Gruyter, pp. 1-17.

Wolfson, N. (1988) 'The bulge: A theory of speech behavior and social distance', in J. Fine (ed.) Second Language Discourse, Norwood, N.J, Ablex, pp. 21-38.

\section{Notes:}

1. For anybody seeking evidence for the basic affective co-operativeness of interactants, I suggest that face effects such as those portrayed here would be the place to look - much more so than in Grice's (1975) misleadingly named 'co-operative principle', which is really about intelligibility, not affect.

2. The instances can be found in the following places: Goffman 1967: 14, 16, $28,35$.

3. Indeed, Goffman's conception of interaction itself is based around mutual physical presence. This approach is clear not only from the fact that nearly all his examples in all of his works assume such presence. It is also entailed, it seems to me, in his argument (e.g. Goffman 1964: 135-156 \& 1981: 141-143) that talk should be studied not as 'conversation' but rather as just one aspect - albeit often a very important one - of encounters between people. This is because when we analyse other kinds of encounter such as telephone or e-mail communication, the non-linguistic aspects tend to be crowded out and all we are left with is talk.)

4. This remark has sometimes been interpreted to mean that face is actually a property of society rather than the individual. I cannot see the value of this interpretation. I believe it stems from a lexico-grammatical confusion - see sections 6.3 and 7 below.

5. Of course, if face is allowed to exist outside interaction as well as inside it, the notion of group face becomes much more feasible. See Sifianou in this volume. 